Archived version from NCDOCKS Institutional Repository http://libres.uncg.edu/ir/asu/

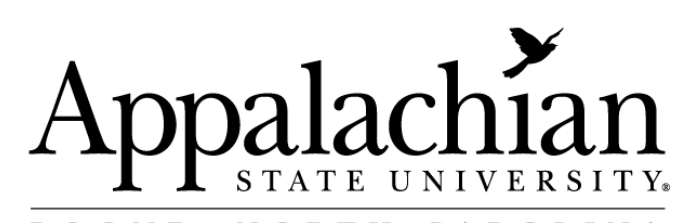

B O O N E, NORT H C A R O L I A

\title{
Reaching Millennials With Nursing History
}

\author{
By: Paul Orkiszewski, Phoebe Pollitt, Andrea Leonard, \& Susan Hayes Lane
}

\begin{abstract}
The North Carolina Nursing History (NCNH) website, a comprehensive, award-winning, and rich educational resource, was developed by nursing and library faculty and staff at Appalachian State University and is being used by nursing faculty and students. Most of today's students prefer to learn with online tools. The advantages of using a digital nursing history website include access to an abundance and diversity of historical content in a student-friendly format.
\end{abstract}

Orkiszewski, Paul, MLIS,M.Music, B.Music, Pollitt, Phoebe,PhD., R.N., Leonard, A., M.L.I.S., \& Lane, Susan Hayes, PhD,M.S.N., R.N. (2016). Reaching millennials with nursing history. Creative Nursing, 22(1), 60-64. doi:http://dx.doi.org/10.1891/1078-4535.22.1.60. Publisher version of record available at: https://search.proquest.com/docview/1764385033/fulltextPDF/76A8657B5C3F4C86PQ/1? accountid $=8337$ 


\title{
Reaching Millennials With Nursing History
}

\author{
Paul Orkiszewski, MLIS, MMusic, BMusic \\ Phoebe Pollitt, PhD, RN \\ Andrea Leonard, MLIS \\ Susan Hayes Lane, PhD, MSN, RN
}
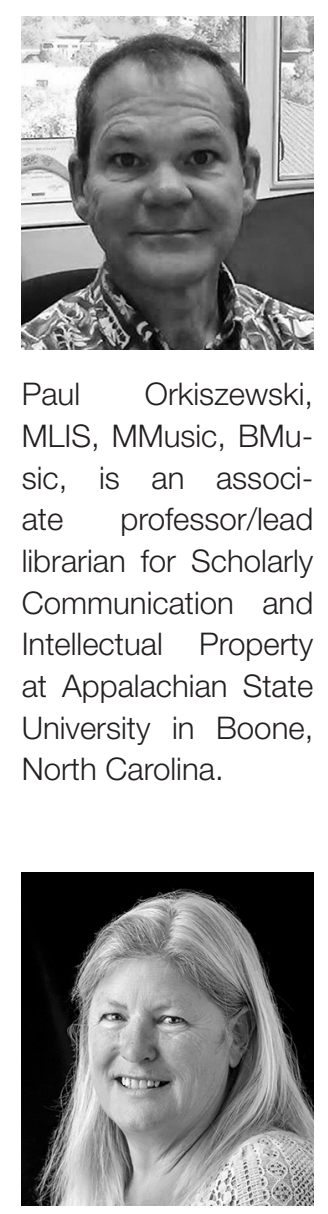

Phoebe Pollitt, PhD, $\mathrm{RN}$, is an associate professor at Appalachian State University in Boone, North Carolina.

\begin{abstract}
The North Carolina Nursing History $(\mathrm{NCNH})$ website, a comprehensive, award-winning, and rich educational resource, was developed by nursing and library faculty and staff at Appalachian State University and is being used by nursing faculty and students. Most of today's students prefer to learn with online tools. The advantages of using a digital nursing history website include access to an abundance and diversity of historical content in a student-friendly format.
\end{abstract}

Keywords: education; nursing; history; technology; digital immigrants; digital natives

\begin{abstract}
"What happens in the present is not an accident. It has a past. In order to understand and change contemporary health system problems, nurse historians examine how these problems emerged, how they influence the present, and how to use that knowledge to design better systems for the future."
\end{abstract}

(Joan Lynaugh, in Fairman \& D'Antonio, 2013, p. 374)

$\mathrm{K}$ nowing nursing history is essential for every nursing student and practicing nurse. Just as knowing our patient's history is imperative for planning and implementing optimal, culturally competent, evidence-based care, knowing our collective professional history is vital for planning and implementing our best professional future. Dock and Stewart (1938), two early American nursing leaders, wrote, "No occupation can be intelligently followed or correctly understood unless it is, at least to some extent, illumined by the light of history" (p. 3).

All of the major nursing and health care organizations recognize the importance of knowing nursing history. The American Nurses Association (ANA) maintains a Hall of Fame highlighting the accomplishments of major historical figures in our profession. ANA's journals often publish articles with historical themes. The American Association of Colleges of Nursing (AACN, 2008) asserts in Standard I, " . . . The study of history, fine arts, literature, and languages 
are important building blocks for developing cultural competence and clinical reasoning." (p. 12).

Standard VIII of the AACN's The Essentials of Baccalaureate Education for Professional Nursing Practice (2008) states that it is critical for baccalaureate students to "Demonstrate an appreciation of the history of and contemporary issues in nursing and their impact on current nursing practice" (p. 28). In addition, the developers of the Quality and Safety Education for Nurses Initiative (n.d.) created a module on Cultivating a Culture of Justice in Nursing Education and Healthcare. As part of the rationale, the authors state, "Before nurses can fully participate and respond effective[ly] to rapidly changing health care settings they must uncover and address the long history of hierarchical and patriarchal structures that prevent full participation" (para. 1).

The U.S. Department of Health and Human Service's Healthy People 2020 website and the National Partnership for Action (2011) declare, "Achieving health equity requires valuing everyone equally with focused and ongoing societal efforts to address avoidable inequalities, historical and contemporary injustices, and the elimination of health and health care disparities" (U. S. Department of Health and Human Services, Office of Disease Prevention and Health Promotion, n.d., para. 4). Finally, the Institute of Medicine (IOM) issued a report in 2010 entitled The Future of Nursing: Leading Change, Advancing Health. The report suggests that nursing faculty may increase the cultural competence and diversity of the nursing workforce by "Distributing literature and pictures related to the history of African Americans in nursing" (IOM, 2010, pp. 129-130). In addition, the IOM and the Robert Wood Johnson Foundation published The Nursing Profession: Development, Challenges, and Opportunities as a companion to the 2010 report, with the first chapter as a comprehensive overview of history of the nursing profession (Mason, Isaacs, \& Colby, 2011).

Knowing and appreciating nursing history allows nursing students and practicing nurses to be inspired to work for the betterment of our profession, to shape a professional identity, and to explore sensitive topics, including race and gender roles that impact the nature of the nursing workforce. By enhancing nurses' cultural competence, the health of current clients is improved. History provides an explanation for current situations and visions for possible futures. In 2009, nurse historian Siobhan Nelson warned of the dangers of the lack of history in nursing curricula:

Historical amnesia is dangerous. ... [L]ack of conversation indicates a lack of historical literacy, it is an illiteracy that has consequences on the way nursing sees itself and is in turn viewed within the health care system and ultimately by the broader community. ... Memory is necessary-we need to know who we are if we have any hope of knowing where we are going." (pp. 781-782)

Typically, historical information related to nursing has only been recorded in more traditional formats and may be effectively invisible to millennial students. New methods of presenting nursing history that meet students in their preferred milieu are therefore imperative.

\section{CHARACTERISTICS OF MILLENIAL LEARNERS}

Technological changes in the wider society have major impacts on teaching and learning in college classrooms. As far back as 2001, Prensky coined the terms digital immigrants and digital natives. Digital immigrants first encountered digital 
and online technology as adults (Prensky, 2001). Digital natives grew up in a technological/online/digital living and learning environment. These groups have fundamentally different ways of gathering, organizing, processing, and retaining information. Given that the average age of doctorally prepared nursing faculty today ranges from 57.7 to 61.7 years (AACN, 2015), Prensky's dichotomy is still relevant in nursing classrooms.

Johnson and Romanello (2005) identified that the millennial generation of nursing students are focused on enthusiastic and collaborative learning environments. In addition, millennial students are digitally literate and continuously connected via technological advances (Skiba, 2005). Billings, Skiba, and Conners (2005) have identified a significant need for educators to better understand generational learners and to recognize an imbalance between students' expectations of the learning environment and the actual environment. Millennial learners almost instinctively use technology and less frequently use traditional formats such as archives, microforms, newspapers, and other print sources (Johnson \& Romanello, 2005; Sherman \& Lynn, 2009). The concept of a comprehensive historical website offers one format for meeting the learning needs of millennial learners related to nursing history.

\section{THE NORTH CAROLINA HISTORY OF NURSING WEBSITE}

Like many cross-disciplinary projects, the nursing history website was the result of several different strands on campus coming together at the right time. Around the same time as the development of the Bachelor of Science in Nursing degree program and the formation of the College of Health Sciences, there were program and resource expansions in the library that would affect the development of the project. One of these expansions was the creation of a digital initiatives team that provided new focus and resources to support online projects. A second was university and program encouragement to reach out across campus for collaboration with other faculty. At the state level, there were strong support and grant possibilities to digitize culturally relevant and historic information.

As with many fields in which women are predominant, academic attention to nursing history has not been robust. There is one dedicated journal, the Nursing History Review. Although other journals address historical issues, there remains room for growth in the literature. There is an even wider scholarship gap in nursing history in North Carolina. For example, a September 2014 Google Scholar search for the phrases New York combined with nursing history returned 4,750 search results, whereas North Carolina and nursing history returned 733 search results. Until 2015, the only book about the history of nursing in North Carolina, written by Mary Lewis Wyche, founder of the North Carolina Nurses Association, was published in 1938. Seeing the need for resources and scholarship, we were inspired by a website on nursing maintained by the Virginia Commonwealth School of Nursing; this website is no longer available.

These currents started to come together with an initial meeting between nursing faculty and the health sciences librarian in 2008. A library project team formed around the idea of working on a large-scale web project. We received a planning grant and proceeded to work on larger collaborative grant proposals including a proposal to partner with the Duke University Medical Archives, the North Carolina State Archives, and smaller archives such as those of the Cherokee Indian 
Museum, and historically African American North Carolina Central University, to digitize their most significant holdings related to nursing. Together, the team compiled resources and designed the North Carolina Nursing History (NCNH) site that went live in summer of 2010.

There are two primary goals for the website: to educate users through engaging content about nursing historical development in North Carolina and to assist scholars with research on North Carolina nursing history by offering primary sources in digital form. The website offers information that appeals to nurses and nursing students, including audio and video recordings of early nurses in various practice settings, photographs, and primary documents. Nursing faculty in various courses are using content from the website to create appealing, interactive learning experiences.

\section{CONCLUSION}

The NCNH website offers value to nursing curricula through various historical content related to individuals, organizations, and trends in nursing history. Although these concepts can be applied in face-to-face didactic learning environments, nursing programs across the nation have experienced an escalation in student preference for online education programs and integration of online educational experiences into face-to-face settings.

Recommendations include the development of nursing historical websites for each state, infusion of nursing history through online nursing history websites into nursing curricula at various levels, and the assessment of learners' needs and preferences related to the use of online resources in learning activities both in the online and face-to-face didactic environment.

Strengthening the nursing history curriculum in our nursing school programs is crucial. Developing teaching strategies using online resources is critical, given today's "digital native" students. Through a cross-disciplinary effort, a nursing history website can be a cornerstone of any nursing history curriculum.

\section{REFERENCES}

American Association of Colleges of Nursing. (2008). The essentials of baccalaureate education for professional nursing practice. Washington, DC: Author.

American Association of Colleges of Nursing. (2015). Nursing faculty shortage. Retrieved from http://www.aacn.nche.edu

Billings, D., Skiba, D., \& Conners, H. (2005). Best practices in web-based courses: Generational differences across undergraduate and graduate nursing students. Journal of Professional Nursing, 21(2), 126-133.

Dock, L. L., \& Stewart, I. M. (1938). A short history of nursing (4th ed.). New York, NY: Putnam.

Fairman, J., \& D'Antonio, P. (2013). History counts: How history can shape our understanding of health policy. Nursing Outlook, 61, 346-352.

Institute of Medicine. (2010). The future of nursing: Leading change, advancing health. Retrieved from http://books.nap.edu

Johnson, S., \& Romanello, M. (2005). Generational diversity: Teaching and learning approaches. Nurse Educator, 30(5), 212-216.

Mason, D. J., Isaacs, S. L., \& Colby, D. C. (Eds.). (2011). The nursing profession: Development, challenges and opportunities. San Francisco, CA: Jossey-Bass. 
Nelson, S. (2009). Historical amnesia and its consequences-The need to build histories of practice. Texto \& Contexto-Enfermagem, 18(4), 781-787. Retrieved from http:/ / www .scielo.br/scielo.php?script=sci_arttext\&pid=S0104-07072009000400021

Prensky, M. (2001). Digital natives, digital immigrants. On the Horizon, 9(5), 1-6.

Quality and Safety Education for Nurses. (n.d.). Cultivating a culture of justice in nursing education and healthcare. Retrieved from http:/ / www.qsen.org/courses/learning-modules/ module-thirteen /

Sherman, R., \& Lynn, C. (2009). Teaching the net set. Journal of Nursing Education, 48(7), $359-360$.

Skiba, D. (2005). The millennials: Have they arrived at your school of nursing? Nursing Education Perspectives, 25(6), 370-371.

U.S. Department of Health and Human Services, National Partnership for Action. (2011). Health equity and disparities. Retrieved from http://minorityhealth.hhs.gov/npa/ templates /browse.aspx?lvl=1\&lvlid=34

U. S. Department of Health and Human Services, Office of Disease Prevention and Health Promotion. (n.d.). Disparities. Retrieved from http://www.healthypeople.gov 